\title{
STEM CELLS FOR TOOTH ENGINEERING
}

\author{
G. Bluteau ${ }^{1 *}$, H-U. Luder ${ }^{1}$, C. De Bari², T. A. Mitsiadis ${ }^{1 *}$ \\ ${ }^{1}$ Department of Orofacial Development and Structure, Institute of Oral Biology, ZZMK, Faculty of Medicine, \\ University of Zurich, Plattenstrasse 11, CH 8032 Zurich, Switzerland. \\ ${ }^{2}$ Department of Medicine and Therapeutics, Institute of Medical Sciences, University of Aberdeen, Aberdeen AB25
} 2ZD, UK.

\begin{abstract}
Tooth development results from sequential and reciprocal interactions between the oral epithelium and the underlying neural crest-derived mesenchyme. The generation of dental structures and/or entire teeth in the laboratory depends upon the manipulation of stem cells and requires a synergy of all cellular and molecular events that finally lead to the formation of tooth-specific hard tissues, dentin and enamel. Although mesenchymal stem cells from different origins have been extensively studied in their capacity to form dentin in vitro, information is not yet available concerning the use of epithelial stem cells. The odontogenic potential resides in the oral epithelium and thus epithelial stem cells are necessary for both the initiation of tooth formation and enamel matrix production. This review focuses on the different sources of stem cells that have been used for making teeth in vitro and their relative efficiency. Embryonic, post-natal or even adult stem cells were assessed and proved to possess an enormous regenerative potential, but their application in dental practice is still problematic and limited due to various parameters that are not yet under control such as the high risk of rejection, cell behaviour, long tooth eruption period, appropriate crown morphology and suitable colour. Nevertheless, the development of biological approaches for dental reconstruction using stem cells is promising and remains one of the greatest challenges in the dental field for the years to come.
\end{abstract}

Keywords: Stem cells, odontoblast, dentin, ameloblasts, enamel, tooth, incisor, human.

*Address for correspondence:

Gilles Bluteau or Thimios Mitsiadis

University of Zurich, Faculty of Medicine,

Institute of Oral Biology, ZZMK,

Plattenstrasse 11, CH 8032 Zurich, Switzerland.

Tel: +41446343197

Tel: +41446343390

Fax: +41 446343310

E-mail: gilles.bluteau@zzmk.uzh.ch or thimios.mitsiadis@zzmk.uzh.ch

\section{Introduction}

Teeth are highly mineralized organs resulting from sequential and reciprocal interactions between the oral epithelium and the underlying cranial neural crest-derived mesenchyme (Duailibi et al., 2006; Mitsiadis, 2001) (Fig. 1). Tissue recombination experiments point out that the oral epithelium contains the inductive capability for odontogenesis. This potential allows conditioning of the underlying mesenchyme, which in turn regulates the differentiation of epithelial cells. The importance of cranial neural crest-derived cells in odontogenesis has been shown in experiments where transplantation of mouse neural crest cells into chick embryos allowed growth of tooth germs (Mitsiadis et al., 2003). Numerous growth factors have been shown to be involved in different stages of the embryonic tooth development (i.e. initiation, morphogenesis, cytodifferentiation). Members of the Transforming Growth Factor beta (TGF $\beta$ ) superfamily such as Bone Morphogenic Protein 2 (BMP-2) and BMP4 are key signalling molecules in regulating epithelialmesenchymal interactions during odontogenesis (Kratochwil et al., 1996; Nadiri et al., 2004; Vainio et al., 1993). Molecules of the Fibroblast Growth Factor (FGF) family such as FGF-3, FGF-4, FGF-8 and FGF-10 are involved in cell proliferation and regulate expression of specific target genes in teeth (Bei and Maas, 1998; Kettunen et al., 1998, 2000). Wnt proteins such as Wnt3 , Wnt-7b, Wnt-10a and Wnt-10b have essential roles as regulators of cell proliferation, migration and differentiation during tooth initiation and morphogenesis (Dassule and McMahon, 1998). Other diffusible factors such as sonic hedgehog (shh) also contribute to both initiation and subsequent dental morphogenesis (Khan et al., 2007).

Two major cell types are involved in dental hard tissue formation: the mesenchyme-originated odontoblasts that are responsible for the production of dentin and the epithelium-derived ameloblasts that form the enamel (Fig. 1). Odontoblasts are columnar post-mitotic cells that form a layer in contact with the dentin. Odontoblastic processes are formed at their distal part, penetrate the dentin and participate in the secretion of dentin matrix and minerals. The matrix is composed of collagen $(90 \%)$ and noncollagenous proteins such as Dentin Sialophosphoprotein (DSPP) and Dentin Matrix Protein 1 (DMP-1). The deposition of apatite minerals on this matrix gives rise to the mature calcified dentin.

Enamel is secreted by ameloblasts along the dentinoenamel junction. Enamel is mainly composed of hydrophobic proteins such as amelogenin, ameloblastin, 


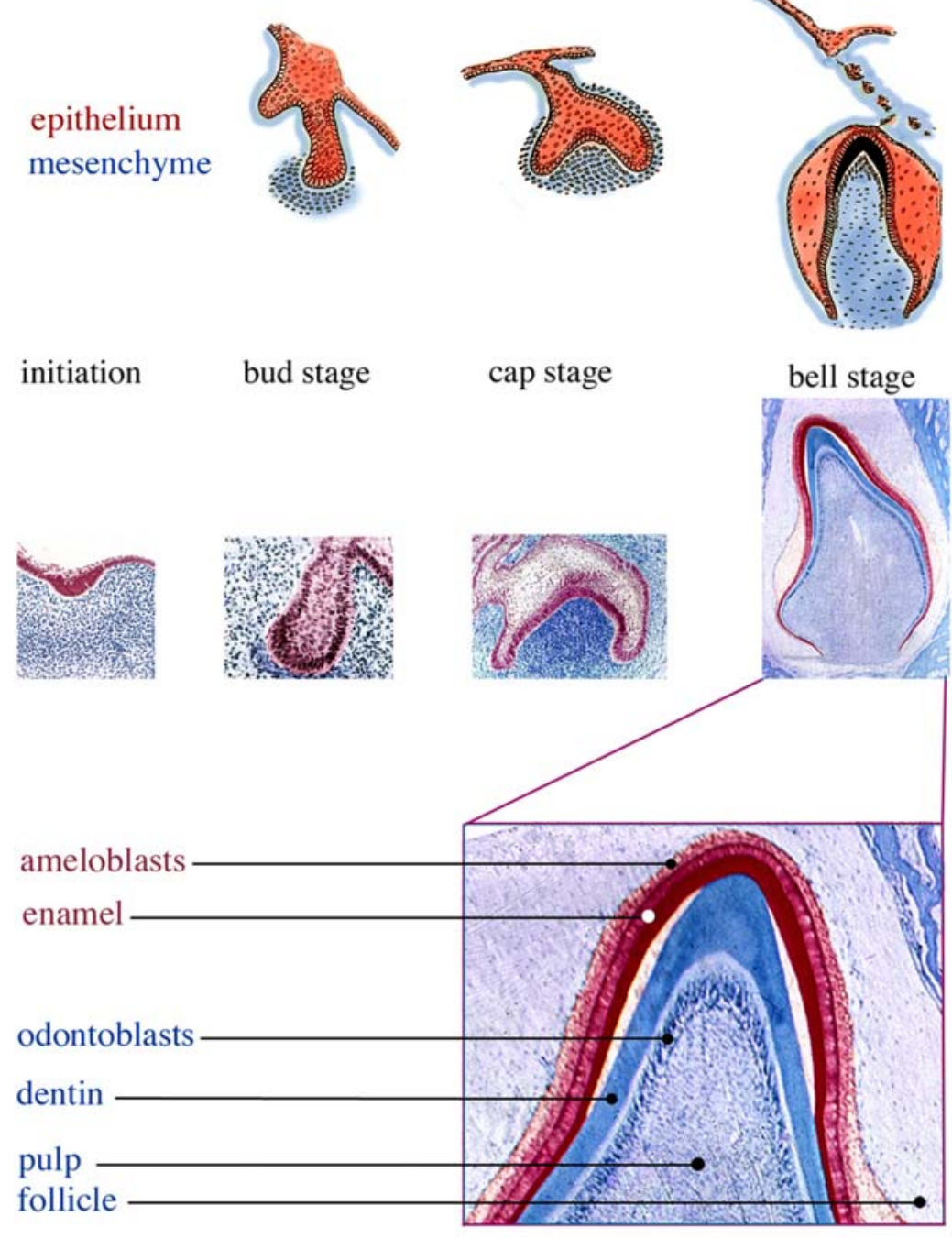

Figure 1. Schematic illustration and histological sections showing the different stages of tooth development in humans. The sections were stained with haematoxylin. Orange colour indicates epithelial tissues and epithelial derivatives (ameloblasts and enamel) while blue colour shows mesenchymal tissues and mesenchyme derivatives (odontoblasts, dentin, dental pulp and follicle). enamelin, amelotin, tuftelin and ODAM (odontogenic ameloblast associated proteins) (Sire et al., 2007). Shortly after enamel deposition, the formation of the root starts as a consequence of cell proliferation in the inner and outer dental epithelia at the cervical loop area. Cells from the dental follicle give rise to cementoblasts (forming the cementum that covers the dentin of the root), fibroblasts (generating the periodontal ligament) and osteoblasts (elaborating the alveolar bone). Cementum, periodontal ligament and alveolar bone are the periodontal tissues that support teeth into the oral cavity.

Tooth loss or absence is a common and frequent situation that can result from numerous pathologies such as periodontal and carious diseases, fractures, injuries or even genetic alterations. In most cases this loss is not critical, but for aesthetical, psychological and medical reasons (e.g. genetic aberrations) replacement of the missing teeth is important. Recent efforts made in the field of biomaterials have led to the development of dental implants composed of biocompatible materials such as titanium that can be inserted in the maxillary and/or mandibular bone to replace the missing teeth. However, implants are still not completely satisfactory and their successful use greatly depends on their osteointegration. The quantity and quality of the bone, as well as its interaction with the surface of the implant are some crucial parameters that can influence the achievement of the operation. Although innovative materials and techniques (e.g. surface treatment) have been used for the improvement of implant osteointegration (reviewed by Le Guehennec et al., 2007), the metal/bone interface does not ensure complete integration of the implant, thus reducing its performance and long-term stability. Furthermore, dental implant technology is dependent on bone volume, as devices (i.e., peg) can be implanted only in patients possessing a sufficient amount of bone. Quite often there is a need for alveolar bone volume increase before any implant fixing. To overcome these difficulties, new ideas and approaches have emerged recently from the quickly developing fields of stem cell technology and tissue engineering.

\section{Stem cells in regenerative medicine}

A stem cell is defined as a cell that can continuously produce unaltered daughters and, furthermore, has the ability to generate cells with different and more restricted properties. Stem cells can divide either symmetrically (allowing the increase of stem cell number) or asymmetrically. Asymmetric divisions keep the number of stem cells unaltered and are responsible for the generation of cells with different properties. These cells can either multiply (progenitors or transit amplifying cells) 
or be committed to terminal differentiation. Progenitors and transit amplifying cells have a limited lifespan and therefore can only reconstitute a tissue for a short period of time when transplanted. In contrast, stem cells are selfrenewing and thus can generate any tissue for a lifetime. This is a key property for a successful therapy. The capacity to expand stem cells in culture is an indispensable step for regenerative medicine, and a considerable effort has been made to evaluate the consequences of the cultivation on stem cell behaviour.

Stem cells cannot be identified with certainty in any tissue: scientists rely on indirect properties such as the expression of a repertoire of surface proteins, slow cell cycle, clonogenicity, or an undifferentiated state. However, none of these criteria are specific. The evaluation of selfrenewal is the ultimate way to show "stemness", which relies on the isolation and transplantation of a putative stem cell (clonal analysis) followed by its serial transplantation and long-term reconstitution of a tissue.

During recent years, stem cells have been used extensively in many medical disciplines for the repair and/ or regeneration of defective tissues and organs (e.g. bone, ligament, heart). New therapeutic approaches are largely inspired and based on our knowledge of embryonic development. The aim of regenerative medicine is to stepwise re-create in vitro all the mechanisms and processes that nature uses during initiation and morphogenesis of a given organ. In this context, stem cell research offers an amazing and seductive potential for body homeostasis, repair, regeneration and pathology. The possibility of manipulating stem cells in situ using specific signalling molecules or by expanding them ex vivo is an exciting outcome of basic research. Hence, regenerative medicine has become a fashionable field and the isolation and manipulation of embryonic and adult (or post-natal) stem cells for the creation of new functional organs that will replace the missing or defective organs constitutes an enormous challenge. Embryonic and adult stem cells have been under intense investigation that focuses on the in vitro development of new organs such as hair, skin and bone. Adult stem cells (ASC), which possess a restricted potential of differentiation, can easily be isolated from a patient and after in vitro amplification and/or differentiation could be re-injected to the same patient thus avoiding immune rejection, as is the case for allografts or xenografts. Since numerous problems remain, the ideal protocol for human pathologies is far away from being used. However, the knowledge in stem cell technology is increasing quickly in all medical disciplines and dictates the need for new strategic approaches in all fields, including reparative dentistry. Stem cell therapy constitutes a common challenge for dentists as well as biologists.

\section{Dental stem niches and other stem cell sources for the development of teeth in vitro or ex vivo}

As tooth formation results from epithelial-mesenchymal interactions, two different populations of stem cells have to be considered: epithelial stem cells (EpSC), which will give rise to ameloblasts, and mesenchymal stem cells (MSC) that will form the odontoblasts, cementoblasts, osteoblasts and fibroblasts of the periodontal ligament. Thus, tooth engineering using stem cells is based on their isolation, association and culture as recombinants in vitro or ex vivo conditions to assess firstly tooth morphogenesis and secondly cell differentiation into tooth specific cells that will form dentin, enamel, cementum and alveolar bone. Various approaches could be used according to the origin of stem cells. Many recent studies have focused on the localization of sites of adult tissues/organs where specific ASC populations reside. ASC are quiescent, slow-cycling, undifferentiated cells, which are surrounded by neighbouring cells and extracellular matrix. This microenvironment is specific for each stem cell compartment but is likely to be influenced by common factors such as vasculature or loading pressure. The specialized microenvironment, housing ASC and transientamplifying cells (TAC), forms a "niche". Understanding these microenvironments and their regulation is the key for the successful reproduction of such niches and for the ex vivo engineering of an organ with ensured functional homeostasis.

In teeth, two different stem cell niches have been suggested: the cervical loop of rodent incisor for EpSC (Harada et al., 1999; Mitsiadis et al., 2007) and a perivascular niche in adult dental pulp for MSC (Shi and Gronthos, 2003). In rodent incisors the proliferation of EpSC, which is located at the cervical loop area, is governed by signals from the surrounding mesenchyme. FGF signalling (mainly FGF-3 and FGF-10) is of particular importance since it is linked to the Notch pathway (Thesleff et al., 2007). Molecules such as BMPs, Activin and Follistatin are also expressed inside the stem cell niche and are known to regulate it's maintenance and functionality through a complex integrative network (Mitsiadis et al., 2007; Thesleff et al., 2007; Wang et al., 2007).

In the dental pulp, MSCs are thought to reside in a perivascular niche (Shi and Gronthos, 2003), but little is known on the exact location and molecular regulation of this niche. The Eph receptor tyrosine kinase family of guidance molecules appears to be involved in the maintenance of the human dental pulp perivascular niche (Stokowski et al., 2007). EphB and its ligand Ephrin-B were shown to inhibit MSC migration and attachment via the MAPK pathway through unidirectional and bidirectional signalling respectively (Stokowski et al., 2007).

In addition to the dental pulp MSC (Gronthos et al., 2000; Miura et al., 2003), other MSC populations have been isolated from human dental tissues such as the periodontal ligament (Seo et al., 2004, 2005) and the dental follicle (Morsczeck et al., 2005), but nothing is known about the existence of a niche in these tissues.

\section{Mesenchymal stem cells}

MSC can be isolated from different sources. First described in bone marrow (Friedenstein et al., 1970), MSC have been extensively characterized in vitro by the expression of markers such as STRO-1, CD146 or CD44 (Pittenger et al., 1999). STRO-1 is a cell surface antigen used to identify 
osteogenic precursors in bone marrow, CD146 a pericyte marker, and CD44 a mesenchymal stem cell marker. MSC possess a high self-renewal capacity and the potential to differentiate into mesodermal lineages thus forming cartilage, bone, adipose tissue, skeletal muscle and the stroma of connective tissues (Prockop, 1997). The potential of dental MSC for tooth regeneration and repair has been extensively studied in the last years. Below, we discuss mesenchymal progenitors that have been assessed for tooth engineering purposes, such as progenitors derived from teeth and bone marrow.

Stem cells from human exfoliated deciduous teeth (SHED). The isolation of post-natal stem cells from an easily accessible source is indispensable for tissue engineering and clinical applications. Recent findings demonstrated the isolation of mesenchymal progenitors from the pulp of human deciduous incisors (Miura et al., 2003). These cells were named SHED (Stem cells from Human Exfoliated Deciduous teeth) and exhibited a high plasticity since they could differentiate into neurons, adipocytes, osteoblasts and odontoblasts (Miura et al., 2003). In vivo SHED cells can induce bone or dentin formation but, in contrast to dental pulp, DPSC failed to produce a dentin-pulp complex.

Adult dental pulp stem cells (DPSC). After a dental injury, dental pulp is involved in a process called reparative dentinogenesis, where cells elaborate and deposit a new dentin matrix for the repair of the injured site (Mitsiadis and Rahiotis, 2004). It has been shown that adult dental pulp contains precursors capable of forming odontoblasts under appropriate signals (About et al., 2000; About and Mitsiadis, 2001; Alliot-Licht et al., 2005; Gronthos et al., 2000, 2002; Miura et al., 2003; Tecles et al., 2005). Among these signals are the calcium hydroxide or calcium phosphate materials, which constitute pulp-capping materials used by dentists for common dental treatments. Dental pulp progenitors have not been clearly identified but some data suggest that pericytes, which are able to differentiate into osteoblasts, could also differentiate into odontoblasts (Alliot-Licht et al., 2005; Lovschall et al., 2007; Shi and Gronthos, 2003). Tooth repair is a lifetime process thus suggesting that MSC might exist in adult dental pulp. The in vivo therapeutic targeting of these adult stem cells remains to be explored.

Stem cells from the apical part of the papilla (SCAP). Stem cells from the apical part of the human dental papilla (SCAP) have been isolated and their potential to differentiate into odontoblasts was compared to that of the periodontal ligament stem cells (PDLSC) (Sonoyama et al., 2006). SCAP exhibit a higher proliferative rate and appears more effective than PDLSC for tooth formation. Importantly, SCAP are easily accessible since they can be isolated from human third molars.

Stem cells from the dental follicle (DFSC). DFSC have been isolated from follicle of human third molars and express the stem cell markers Notch1, STRO-1 and nestin (Morsczeck et al., 2005). These cells can be maintained in culture for at least 15 passages. STRO-1 positive DFSC can differentiate into cementoblasts in vitro (Kemoun et al., 2007) and are able to form cementum in vivo (Handa et al., 2002). Immortalized dental follicle cells are able to re-create a new periodontal ligament (PDL) after in vivo implantation (Yokoi et al., 2007).

Periodontal ligament stem cells (PDLSC). The PDL is a specialized tissue located between the cementum and the alveolar bone and has as a role the maintenance and support of the teeth. Its continuous regeneration is thought to involve mesenchymal progenitors arising from the dental follicle. PDL contains STRO-1 positive cells that maintain certain plasticity since they can adopt adipogenic, osteogenic and chondrogenic phenotypes in vitro (Gay et al., 2007). It is thus obvious that PDL itself contains progenitors, which can be activated to self-renew and regenerate other tissues such as cementum and alveolar bone (Seo et al., 2004).

Bone marrow derived mesenchymal stem cells (BMSC). BMSC have been tested for their ability to recreate periodontal tissue. These cells are able to form in vivo cementum, PDL and alveolar bone after implantation into defective periodontal tissues. Thus, bone marrow provides an alternative source of MSC for the treatment of periodontal diseases (Kawaguchi et al., 2004). BMSC share numerous characteristics with DPSC and are both able to form bone-like or tooth-like structures. However, BMSC display a lower odontogenic potential than DPSC (Yu et al., 2007), indicating that MSC from different embryonic origins are not equivalent. Indeed, DPSC derive from neural crest cells, whereas BMSC originate from the mesoderm. Furthermore, the comparison of the osteogenic and adipogenic potential of MSC from different origins shows that, even if cells carry common genetic markers, they are not equivalent and are already committed toward a specific differentiation pathway (Musina et al., 2005, 2006). Commitment could arise from conditioning of stem cells by their specific microenvironment or stem cell niche. MSC can also be obtained from several other sources such as synovial membrane ((De Bari et al., 2001, 2003, 2004) and periosteum (De Bari et al., 2006). As these cell populations display distinctive biological properties depending upon their tissue of origin (De Bari and Dell'accio, 2008), it remains to be explored which source might be used for an optimal tooth development for clinical application.

In search of epithelium-originated dental stem cells Although significant progress has been made with MSC, there is no information available for dental EpSC in humans. The major problem is that dental epithelial cells such as ameloblasts and ameloblasts precursors are eliminated soon after tooth eruption. Therefore, epithelial cells that could be stimulated in vivo to form enamel are not present in human adult teeth. Stem cell technology appears to be the only possibility to re-create an enamel surface.

Epithelial stem cells from developing molars. Several studies describe the use of EpSC isolated from newborn or juvenile animals, usually from third molar teeth. In these studies, epithelia were removed and cells dissociated enzymatically. Precursors were then amplified and associated with MSC (originated from the same tooth) in 

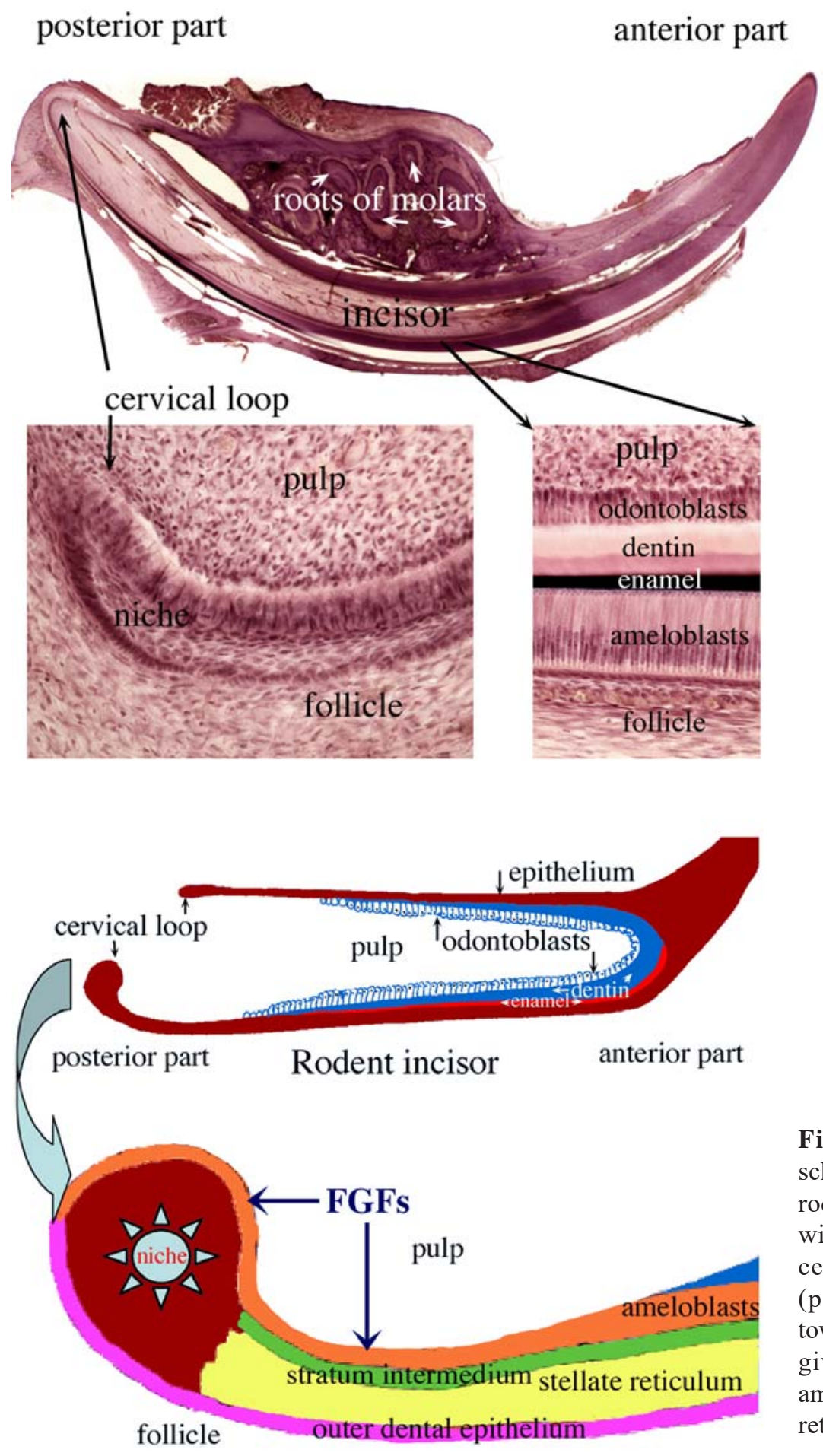

Figure 2. Histological sections and schematic representation of a mandibular rodent incisor. The sections were stained with haematoxylin/eosin. Epithelial stem cells located in the cervical loop area (posterior part of the incisor) migrate towards the anterior part of the incisor and give rise to four epithelial cell layers: ameloblasts, stratum intermedium, stellate reticulum and outer dental epithelium.

vitro in contact with biomaterials such as collagen sponges or synthetic polymers (Honda et al., 2005, 2007b; Young et al., 2002). These approaches are promising for tooth formation and/or regeneration. However, the clinical application is difficult, if not unrealistic, since it would require the donation of a tooth germ from children. The use of autologous stem cells is desirable but raises the question of a good and reliable source.

Epithelial stem cells from the labial cervical loop of rodent incisor. The rodent incisor is a unique model for studying dental EpSC since, in contrast to human incisors or other vertebrates, this tooth grows throughout life. An
EpSC niche, which is located in the apical part of the rodent incisor epithelium (cervical loop area), is responsible for a continuous enamel matrix production (Harada et al., 1999; Kawano et al., 2004; Mitsiadis et al., 1998, 2007; Smith and Warshawsky, 1975). In this highly proliferative area, undifferentiated epithelial cells migrate toward the anterior part of the incisor and give rise to ameloblasts (Fig. 2). Although these findings are important for understanding the mechanisms of stem cell homing, renewal and differentiation, this source of dental EpSC cannot be used for treatment in humans since it would require the introduction of rodent cells in the human mouth. 
Dental EpSC can be isolated from post-natal teeth but exhibit complex problems that strongly limit their clinical application in humans. Other sources are thus required. Ideally these sources should be easily accessible, available from adult individuals and the derived cells must have potential for enamel matrix production. The use of nondental EpSC will only be possible with the transfer of genes, creating an odontogenic potential to non-dental epithelia prior to any association with mesenchymal cells. This is certainly one of the most exciting goals of the next decade in tooth engineering.

\section{Association of epithelial and mesenchymal stem cells}

Since teeth are formed from two different tissues, building a tooth logically requires the association/cooperation of odontogenic mesenchymal and epithelial cells. The recombination of dissociated dental epithelial and mesenchymal tissues leads to tooth formation both in vitro and in vivo (Amar et al., 1989; Yoshiba et al., 1998). Numerous attempts have been made in order to form teeth in vivo with very promising results. Single cell suspensions obtained from rat, pig or mice tooth germs have been seeded onto the surface of selected biomaterials (e.g. collagen-coated polyglycolic acid, calcium phosphate material, collagen sponges) and successfully re-implanted into the omentum of immunocompromised animals (Duailibi et al., 2004; Honda et al., 2006, 2007a, 2007b; Hu et al., 2006; Robey, 2005; Young et al., 2002). All these reports describe the presence of both dentin and enamel. This indicates that the recombined cells could re-organize themselves and form individual layers and, furthermore, that they can differentiate properly into odontoblasts and ameloblasts. In most of these studies the cells were directly seeded onto biomaterials without any additional in vitro procedure. In studies including in vitro steps before the in vivo transplantation, the results could be influenced by several critical parameters such as the presence or absence of serum, the type of serum, the composition of culture media, the cell density and the ratio between epithelial and mesenchymal cells. For these reasons, a definitive and universal protocol for tooth formation does not exist so far.

Making entire teeth with enamel and dentin structures in vivo is a reality and not a utopia. However, these bioengineered teeth have been produced in ectopic sites and are still missing some essential elements such as the complete root and periodontal tissues that allow correct anchoring into the alveolar bone. Recently, a new approach has been proposed for growing teeth in the mouse mandible (Nakao et al., 2007). In this study, epithelial and mesenchymal cells were sequentially seeded into a collagen gel drop and then implanted into the tooth cavity of adult mice. With this technique the presence of all dental structures such as odontoblasts, ameloblasts, dental pulp, blood vessels, crown, periodontal ligament, root and alveolar bone could be observed (Nakao et al., 2007). Thus, the implantation of these tooth germs in the mandible allowed their development, maturation and eruption (Fig. 3 ) indicating that stem cells could be used in the future for the replacement of missing teeth in humans.
Epithelial stem cells

Mesenchymal stem cells

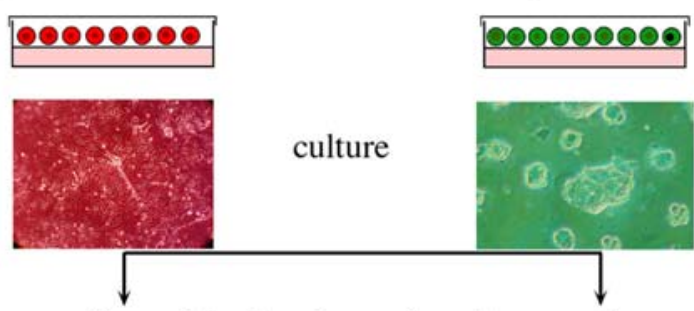

Recombined and co-cultured stem cells

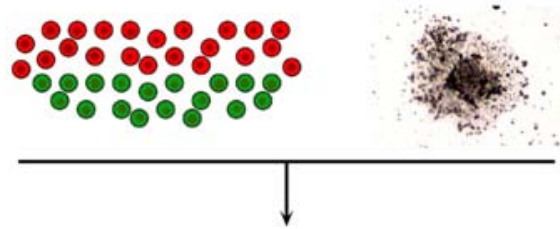

Tooth germ

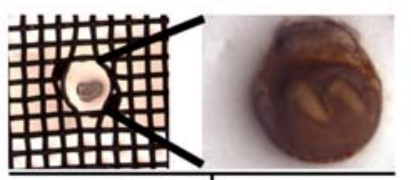

Transplantation

Tooth

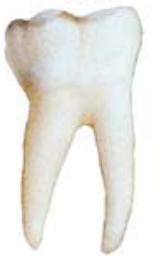

Figure 3. Use of stem cells for tooth formation in vitro and ex vivo. A tooth germ can be created in vitro after co-culture of isolated epithelial and mesenchymal stem cells. This germ could be implanted into the alveolar bone and finally develop into a fully functional tooth.

Despite the outstanding advances in tooth bioengineering, such a technology can not be applied to human restorative dentistry for one simple reason: the epithelial and mesenchymal cells used for tooth reconstruction are of dental origin and have been given by a donor. The challenge that remains is to find out new and easily accessible sources of both epithelial and mesenchymal stem cells that can be reprogrammed for an odontogenic potential and then associated to form a fully functional tooth. One alternative could be the use of genetically modified cells expressing specific genes (e.g. transgenes, siRNA) or with a specifically deleted gene (e.g. knock-in, knock-out). Ideally, this approach should provide a non-limited source of cells and introduce new genetic information to reprogram a non-dental cell to acquire odontogenic properties. For example, p53-deficient mice were used to establish dental epithelial clonal cell lines subsequently associated with mesenchymal cells to bioengineer teeth in vivo (Komine et al., 2007). These cell lines demonstrated heterogeneous outcomes in terms of regeneration depending on their differentiation state. Although this technique provides us with an unlimited source of epithelial cells and shows the potential of 
genetically modified cells that can be used for tooth engineering (Komine et al., 2007), many questions have to be resolved. Which gene should be used to trigger an odontogenic program? Is only one gene enough to reprogram a cell toward a tooth specific cell?

\section{Conclusions}

Taken together these recent findings clearly indicate that the control of morphogenesis and cytodifferentiation is a challenge that necessitates a thorough understanding of the cellular and molecular events involved in development, repair and regeneration of teeth. The identification of several types of epithelial and mesenchymal stem cells in the tooth and the knowledge of molecules involved in stemcell fate is a significant achievement. In vitro and in vivo experiments using these cells have provided promising results illustrated by the generation of a complete tooth with all dental structures including cells and extracellular matrix deposition (Nakao et al., 2007). However, many problems remain to be addressed before considering the clinical use of these technologies. The use of animal cells for human diseases is restricted by immune rejection risks. Additionally, isolating autologous stem cells requires a source of easily accessible cells without the need for a surgery. It may be possible to replace dental mesenchymal stem cells with stem cells of another origin. At present, it does not appear that this is the case for epithelial stem cells. A reliable source of EpSC for that purpose remains to be determined. Alternative solutions such as the use of artificial crowns are considered. The engineering of tridimensional matrices (either polylactic acid polymers or collagen sponges) which a composition more or less similar to that of the organs to reconstruct, and the addition of growth factors such as FGF, BMP or PDGF might facilitate the transplantation and the differentiation of stem cells (Fig. 4). However, the engineering of tooth substitutes is hard to scale up, costly, time-consuming and incompatible with the treatment of extensive tooth loss. Scientific knowledge is not enough and the main challenge in stem-cell therapy is to find a compromise between the benefits to the patients, regulatory agencies, increased stem cell requirements, costs, coverage by health insurance and the role of pharmaceutical companies.

\section{Acknowledgments}

Authors would like to thank Dr. Hervé Lesot (Université Louis Pasteur, Strasbourg, France) for helpful discussions and suggestions. This work was supported by a grant from the Swiss National Foundation (SNF).

\section{References}

About I, Bottero MJ, de Denato P, Camps J, Franquin JC, Mitsiadis TA (2000) Human dentin production in vitro. Exp Cell Res 258:33-41.

About I, Mitsiadis TA (2001) Molecular aspects of tooth pathogenesis and repair: in vivo and in vitro models. Adv Dent Res 15:59-62.

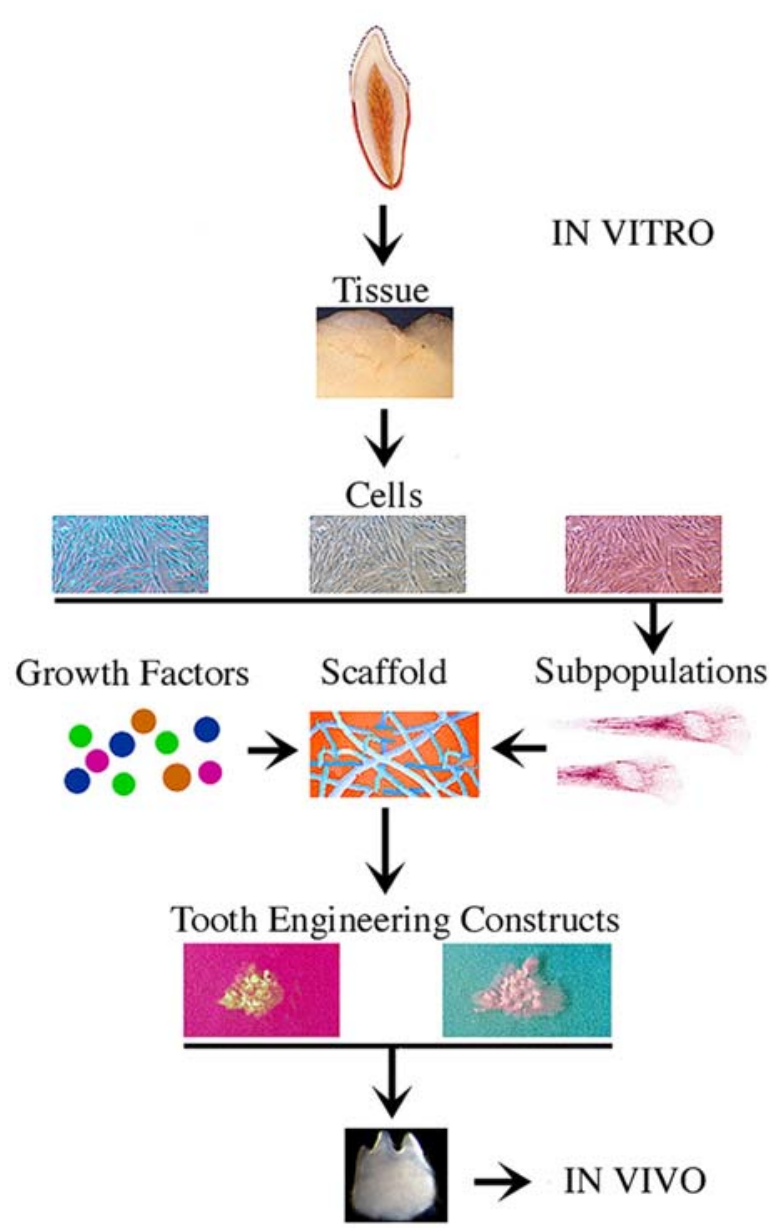

Figure 4. Construction of a bioengineered tooth. The association of tooth-derived stem cells with defined scaffolds in the presence of growth factors allows the creation of tooth specific constructs such as crown and root of missing parts of an injured tooth. These biological constructs could be used in dental clinics as substitutes for metal implants, crowns and restorative dental materials.

Alliot-Licht B, Bluteau G, Magne D, Lopez-Cazaux S, Lieubeau B, Daculsi G, Guicheux J (2005) Dexamethasone stimulates differentiation of odontoblast-like cells in human dental pulp cultures. Cell Tissue Res 321:391-400.

Amar S, Luo W, Snead ML, Ruch JV (1989) Amelogenin gene expression in mouse incisor heterotopic recombinations. Differentiation 41:56-61.

Bei M, Maas R (1998) FGFs and BMP4 induce both Msx 1-independent and Msx1-dependent signaling pathways in early tooth development. Development 125:4325-4333.

Dassule HR, McMahon AP (1998) Analysis of epithelial-mesenchymal interactions in the initial morphogenesis of the mammalian tooth. Dev Biol 202:215227.

De Bari C, Dell'accio F (2008) Cell therapy: a challenge in modern medicine. Biomed Mater Eng 18:S1117.

De Bari C, Dell'Accio F, Luyten FP (2004) Failure of in vitro-differentiated mesenchymal stem cells from the 
synovial membrane to form ectopic stable cartilage in vivo. Arthritis Rheum 50:142-150.

De Bari C, Dell'Accio F, Tylzanowski P, Luyten FP (2001) Multipotent mesenchymal stem cells from adult human synovial membrane. Arthritis Rheum 44:19281942.

De Bari C, Dell'Accio F, Vandenabeele F, Vermeesch JR, Raymackers JM, Luyten FP (2003) Skeletal muscle repair by adult human mesenchymal stem cells from synovial membrane. J Cell Biol 160:909-918.

De Bari C, Dell'Accio F, Vanlauwe J, Eyckmans J, Khan IM, Archer CW, Jones EA, McGonagle D, Mitsiadis TA, Pitzalis C, Luyten FP (2006) Mesenchymal multipotency of adult human periosteal cells demonstrated by single-cell lineage analysis. Arthritis Rheum 54:12091221.

Duailibi MT, Duailibi SE, Young CS, Bartlett JD, Vacanti JP, Yelick PC (2004) Bioengineered teeth from cultured rat tooth bud cells. J Dent Res 83:523-528.

Duailibi SE, Duailibi MT, Vacanti JP, Yelick PC (2006) Prospects for tooth regeneration. Periodontol 2000 41:177187.

Friedenstein AJ, Chailakhjan RK, Lalykina KS (1970) The development of fibroblast colonies in monolayer cultures of guinea-pig bone marrow and spleen cells. Cell Tissue Kinet 3:393-403.

Gay I, Chen S, Macdougall M (2007) Isolation and characterization of multipotent human periodontal ligament stem cells. Orthod Craniofac Res 10:149-160.

Gronthos S, Brahim J, Li W, Fisher LW, Cherman N, Boyde A, DenBesten P, Robey PG, Shi S (2002) Stem cell properties of human dental pulp stem cells. J Dent Res 81: 531-535.

Gronthos S, Mankani M, Brahim J, Robey PG, Shi S (2000) Postnatal human dental pulp stem cells (DPSCs) in vitro and in vivo. Proc Natl Acad Sci USA 97: 1362513630.

Handa K, Saito M, Tsunoda A, Yamauchi M, Hattori S, Sato S, Toyoda M, Teranaka T, Narayanan AS (2002) Progenitor cells from dental follicle are able to form cementum matrix in vivo. Connect Tissue Res 43: 406408.

Harada H, Kettunen P, Jung HS, Mustonen T, Wang YA, Thesleff I (1999) Localization of putative stem cells in dental epithelium and their association with Notch and FGF signaling. J Cell Biol 147: 105-120.

Honda MJ, Shimodaira T, Ogaeri T, Shinohara Y, Hata K, Ueda M (2006) A novel culture system for porcine odontogenic epithelial cells using a feeder layer. Arch Oral Biol 51: 282-290.

Honda MJ, Shinohara Y, Hata KI, Ueda M (2007a) Subcultured odontogenic epithelial cells in combination with dental mesenchymal cells produce enamel-dentin-like complex structures. Cell Transplant 16: 833-847.

Honda MJ, Sumita Y, Kagami H, Ueda M (2005) Histological and immunohistochemical studies of tissue engineered odontogenesis. Arch Histol Cytol 68: 89-101.

Honda MJ, Tsuchiya S, Sumita Y, Sagara H, Ueda M (2007b) The sequential seeding of epithelial and mesenchymal cells for tissue-engineered tooth regeneration. Biomaterials 28: 80-689.
Hu B, Nadiri A, Kuchler-Bopp S, Perrin-Schmitt F, Peters H, Lesot H (2006) Tissue engineering of tooth crown, root, and periodontium. Tissue Eng 12: 2069-2075.

Kawaguchi H, Hirachi A, Hasegawa N, Iwata T, Hamaguchi H, Shiba H, Takata T, Kato Y, Kurihara H (2004) Enhancement of periodontal tissue regeneration by transplantation of bone marrow mesenchymal stem cells. J Periodontol 75: 1281-1287.

Kawano S, Saito M, Handa K, Morotomi T, Toyono T, Seta Y, Nakamura N, Uchida T, Toyoshima K, Ohishi M, Harada H (2004) Characterization of dental epithelial progenitor cells derived from cervical-loop epithelium in a rat lower incisor. J Dent Res 83: 129-133.

Kemoun P, Laurencin-Dalicieux S, Rue J, Farges JC, Gennero I, Conte-Auriol F, Briand-Mesange F, Gadelorge M, Arzate H, Narayanan AS, Brunel G, Salles JP (2007) Human dental follicle cells acquire cementoblast features under stimulation by BMP-2/-7 and enamel matrix derivatives (EMD) in vitro. Cell Tissue Res 329: 283-294.

Kettunen P, Karavanova I, Thesleff I (1998) Responsiveness of developing dental tissues to fibroblast growth factors: expression of splicing alternatives of FGFR1, -2, -3, and of FGFR4; and stimulation of cell proliferation by FGF-2, -4, -8, and -9. Dev Genet 22: 374385.

Kettunen P, Laurikkala J, Itaranta P, Vainio S, Itoh N, Thesleff I (2000) Associations of FGF-3 and FGF-10 with signaling networks regulating tooth morphogenesis. Dev Dyn 219: 322-332.

Khan M, Seppala M, Zoupa M, Cobourne MT (2007) Hedgehog pathway gene expression during early development of the molar tooth root in the mouse. Gene Expr Patterns 7: 239-243.

Komine A, Suenaga M, Nakao K, Tsuji T, Tomooka Y (2007) Tooth regeneration from newly established cell lines from a molar tooth germ epithelium. Biochem Biophys Res Commun 355: 758-763.

Kratochwil K, Dull M, Farinas I, Galceran J, Grosschedl R (1996) Lefl expression is activated by BMP4 and regulates inductive tissue interactions in tooth and hair development. Genes Dev 10: 1382-1394.

Le Guehennec L, Soueidan A, Layrolle P, Amouriq Y (2007) Surface treatments of titanium dental implants for rapid osseointegration. Dent Mater 23: 844-854.

Lovschall H, Mitsiadis TA, Poulsen K, Jensen KH, Kjeldsen AL (2007) Coexpression of Notch3 and Rgs5 in the pericyte-vascular smooth muscle cell axis in response to pulp injury. Int J Dev Biol 51: 715-721.

Mitsiadis T (2001) Bases moléculaires du développement dentaire, In "La dent normale et pathologique” (E. Piette, M. Goldberg, Ed.), De BoeckUniversité Press, Paris, pp19-38.

Mitsiadis TA, Rahiotis C (2004) Parallels between tooth development and repair: conserved molecular mechanisms following carious and dental injury. J Dent Res 83:896902.

Mitsiadis TA, Hirsinger E, Lendahl U, Goridis C (1998) Delta-notch signaling in odontogenesis: correlation with cytodifferentiation and evidence for feedback regulation. Dev Biol 204: 420-431. 
Mitsiadis TA, Cheraud Y, Sharpe P, Fontaine-Perus J (2003) Development of teeth in chick embryos after mouse neural crest transplantations. Proc Natl Acad Sci USA 100: 6541-6545.

Mitsiadis TA, Barrandon O, Rochat A, Barrandon Y, De Bari C (2007) Stem cell niches in mammals. Exp Cell Res 313: 3377-3385.

Miura M, Gronthos S, Zhao M, Lu B, Fisher LW, Robey PG, Shi S (2003) SHED: stem cells from human exfoliated deciduous teeth. Proc Natl Acad Sci USA 100: 5807-5812.

Morsczeck C, Gotz W, Schierholz J, Zeilhofer F, Kuhn U, Mohl C, Sippel C, Hoffmann KH (2005) Isolation of precursor cells (PCs) from human dental follicle of wisdom teeth. Matrix Biol 24: 155-165.

Musina RA, Bekchanova ES, Belyavskii AV, Sukhikh GT (2006) Differentiation potential of mesenchymal stem cells of different origin. Bull Exp Biol Med 141: 147-151.

Musina RA, Bekchanova ES, Sukhikh GT (2005) Comparison of mesenchymal stem cells obtained from different human tissues. Bull Exp Biol Med 139: 504-509.

Nadiri A, Kuchler-Bopp S, Haikel Y, Lesot H (2004) Immunolocalization of BMP-2/-4, FGF-4, and WNT10b in the developing mouse first lower molar. J Histochem Cytochem 52: 103-112.

Nakao K, Morita R, Saji Y, Ishida K, Tomita Y, Ogawa M, Saitoh M, Tomooka Y, Tsuji T (2007) The development of a bioengineered organ germ method. Nat Methods 4: 227-230.

Pittenger MF, Mackay AM, Beck SC, Jaiswal RK, Douglas R, Mosca JD, Moorman MA, Simonetti DW, Craig S, Marshak DR (1999) Multilineage potential of adult human mesenchymal stem cells. Science 284:143147.

Prockop DJ (1997) Marrow stromal cells as stem cells for nonhematopoietic tissues. Science 276: 71-74.

Robey PG (2005) Post-natal stem cells for dental and craniofacial repair. Oral Biosci Med 2: 83-90.

Seo BM, Miura M, Gronthos S, Bartold PM, Batouli S, Brahim J, Young M, Robey PG, Wang CY, Shi S (2004) Investigation of multipotent postnatal stem cells from human periodontal ligament. Lancet 364: 149-155.

Seo BM, Miura M, Sonoyama W, Coppe C, Stanyon R, Shi S (2005) Recovery of stem cells from cryopreserved periodontal ligament. J Dent Res 84: 907-912.

Shi S, Gronthos S (2003) Perivascular niche of postnatal mesenchymal stem cells in human bone marrow and dental pulp. J Bone Miner Res 18: 696-704.
Sire JY, Davit-Beal T, Delgado S, Gu X (2007) The origin and evolution of enamel mineralization genes. Cells Tissues Organs 186: 25-48.

Smith CE, Warshawsky H (1975) Cellular renewal in the enamel organ and the odontoblast layer of the rat incisor as followed by radioautography using $3 \mathrm{H}$-thymidine. Anat Rec 183: 523-561.

Sonoyama W, Liu Y, Fang D, Yamaza T, Seo BM, Zhang C, Liu H, Gronthos S, Wang CY, Shi S, Wang S (2006) Mesenchymal stem cell-mediated functional tooth regeneration in swine. PLoS ONE 1: e79.

Stokowski A, Shi S, Sun T, Bartold PM, Koblar SA, Gronthos S (2007) EphB/ephrin-B interaction mediates adult stem cell attachment, spreading, and migration: implications for dental tissue repair. Stem Cells 25: 156164.

Tecles O, Laurent P, Zygouritsas S, Burger AS, Camps J, Dejou J, About I (2005) Activation of human dental pulp progenitor/stem cells in response to odontoblast injury. Arch Oral Biol 50: 103-108.

Thesleff I, Wang XP, Suomalainen M (2007) Regulation of epithelial stem cells in tooth regeneration. C R Biol 330: 561-564.

Vainio S, Karavanova I, Jowett A, Thesleff I (1993) Identification of BMP-4 as a signal mediating secondary induction between epithelial and mesenchymal tissues during early tooth development. Cell 75: 45-58.

Wang XP, Suomalainen M, Felszeghy S, Zelarayan LC, Alonso MT, Plikus MV, Maas RL, Chuong CM, Schimmang T, Thesleff I (2007) An integrated gene regulatory network controls stem cell proliferation in teeth. PLoS Biol 5: e159.

Yokoi T, Saito M, Kiyono T, Iseki S, Kosaka K, Nishida E, Tsubakimoto T, Harada H, Eto K, Noguchi T, Teranaka $\mathrm{T}$ (2007) Establishment of immortalized dental follicle cells for generating periodontal ligament in vivo. Cell Tissue Res 327: 301-311.

Yoshiba K, Yoshiba N, Aberdam D, Meneguzzi G, Perrin-Schmitt F, Stoetzel C, Ruch JV, Lesot H (1998) Expression and localization of laminin-5 subunits during mouse tooth development. Dev Dyn 211: 164-176.

Young CS, Terada S, Vacanti JP, Honda M, Bartlett JD, Yelick PC (2002) Tissue engineering of complex tooth structures on biodegradable polymer scaffolds. J Dent Res 81: 695-700.

Yu J, Wang Y, Deng Z, Tang L, Li Y, Shi J, Jin Y (2007) Odontogenic capability: bone marrow stromal stem cells versus dental pulp stem cells. Biol Cell 99: 465-474. 